\section{Развитие расчетно- экспериментального метода прогнозирования износа трибологических сопряжений двигателей внутреннего сгорания}

\author{
А. Ю. Шабанов ${ }^{1}$, \\ Д. А. Черепанов \\ Санкт-Петербургский государственный \\ политехнический университет
}

\begin{abstract}
АННОТАЦИЯ
Дана оценка расчетному и статистическому способам прогнозирования изнашивания трибологических сопряжениий двигателей внутреннего сгорания. Рассмотрены проблемы и перспективы развития расчетно-экспериментального метода определения ресурса подшипников скольжения и поршневых колец.
\end{abstract}

Ключевые слова: изнашивание, ресурс, двигатели внутреннего сгорания, подшипники.

\section{SUMMARY}

The estimation of calculation and statistical methods of forecasting of wear process of tribological coupling in the internal combustion engines has been given. Problems and prospects of the design-experiment method development of slide bearings and piston rings lifetime definition have been considered.

Keywords: wear process, lifetime, internal combustion engines, bearings.

Прогнозирование величин износа трибологических сопряжений двигателей внутреннего сгорания (ДВС) представляет интерес как при конструировании двигателей, так и в процессе их эксплуатации. На этапе конструирования нового двигателя основное внимание уделяется проблемам влияния конструктивных и технологических решений, а также всех задаваемых параметров (рабочего процесса, топлива, смазки, охлаждающей жидкости и других) на ресурс, тогда как при эксплуатации возникает проблема влияния на межремонтные сроки условий и режимов работы двигателей в составе установок разнообразного назначения [1]. Основными (определяющими ресурс по износу) узлами трения ДВС являются: «шейка подшипник коленчатого вала» и «поршневые кольца - гильза цилиндров». Известны два способа оценки ресурса деталей машин по их износу: расчетный и статистический, основанный на обработке информации об износах деталей машин в условиях эксплуатации (экспериментальные данные) [2]. Статистический подход успешно может применяться лишь в условиях, когда требуется оценить ресурс двигателя, имею-

${ }^{1}$ Авторы - соответственно доцент и аспирант кафедры ДВС

(C) А. Ю. Шабанов, Д. А. Черепанов, 2003 щего сходные конструкцию и условия эксплуатации с ДВС, по которому имеются экспериментальные данные. Как показал анализ ситуации, в России и в мире в настоящее время не существует единой общепризнанной теории изнашивания и практические инженерные расчеты на износ возможны лишь с помощью расчетно-экспериментальных методов. Применительно к условиям работы трибологических сопряжений двигателя, принципиально возможно использование следующих методов: усталостной теории износа (по И. В. Крагельскому); прогнозирования износа по методу фирмы IBM; расчёта износа сопряжений (по А. С. Проникову); изнашивания с позиций термофлуктуационной теории прочности (по С. Н. Журкову, С. Б. Ратнеру); энергетической теории износа (по Флайшеру); структурно-энергетической теории износа (по Л. И. Погодаеву); метода оценки износа по статистическим данным и ряда других. Оценка применимости осуществлялась исходя из типичных условий работы кольцевых уплотнений и подшипников скольжения - граничное трение скольжения при упругом контакте. Следует отметить, что наиболее развитые современные теории и методы процессов изнашивания взаимно обогащают друг друга, противоречия, как правило, лежат в разных изначальных положениях. Одной из наиболее авторитетных и адаптированных для инженерных расчетов теорий при интересующих нас условиях является усталостная теория изнашивания $[3,6,7]$.

Основу расчетов износа трибосопряжений в этой теории составляет поиск коэффициента изнашивания (скорости износа), называемого безразмерной линейной интенсивностью изнашивания:

$I_{h}=\frac{d H}{d L_{T P}}$,

где $\mathrm{H}$ - величина износа (мм), $\mathrm{L}_{\text {тр }}$ - путь трения (мм). При данном подходе к определению износа расчеты ведутся по двум основополагающим направлениям: для отыскания $\mathrm{I}_{\mathrm{h}}$ [4] и для определения $\mathrm{L}_{\text {тр. }}$.5]. Расчеты проводят для условий так называемого установившегося режима износа $\mathrm{I}_{\mathrm{h}}=$ const (рис. 1).

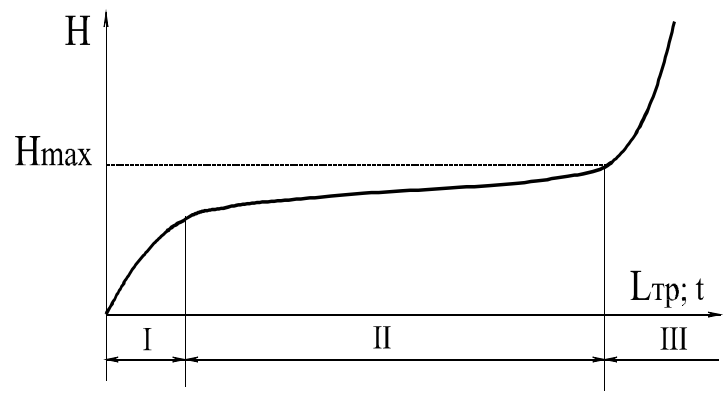

Рис. 1. Общий вид типичной зависимости износа трибосопряжения $\mathrm{H}$ от времени работы $\mathrm{t}$ (пути трения Lтр): I - приработка; II - установившийся режим; III - катастрофический износ

При критическом износе и в условиях приработки расчеты возможны, основной сложностью является 
стремительное изменение во времени контактных параметров узла трения (давления, шероховатости и других). Динамика изменения этих параметров может быть определена только экспериментально, что связано с известными трудностями. В реальных условиях эксплуатации двигателя трибосопряжения работают, в том числе, и на неустановившихся режимах: холодного пуска, малых частот вращения и предельных нагрузок. Перед тем как отметить пути учета изнашивания узлов трения на этих режимах, рассмотрим методику расчета основных узлов трения ДВС на установившемся режиме изнашивания. Процесс износа в подшипниковых узлах скольжения осуществляется при вращательном движении, тогда как в кольцевых уплотнениях - при возвратнопоступательном движении. Работоспособность метода определим на примере соединения «шейка - подшипник коленчатого вала». Для двигателя ВАЗ-2112, имеющего диаметр цилиндра $82 \mathrm{Mм}$, ход поршня 71 мм, расчет первого шатунного подшипника показал следующие результаты (рис. 2).
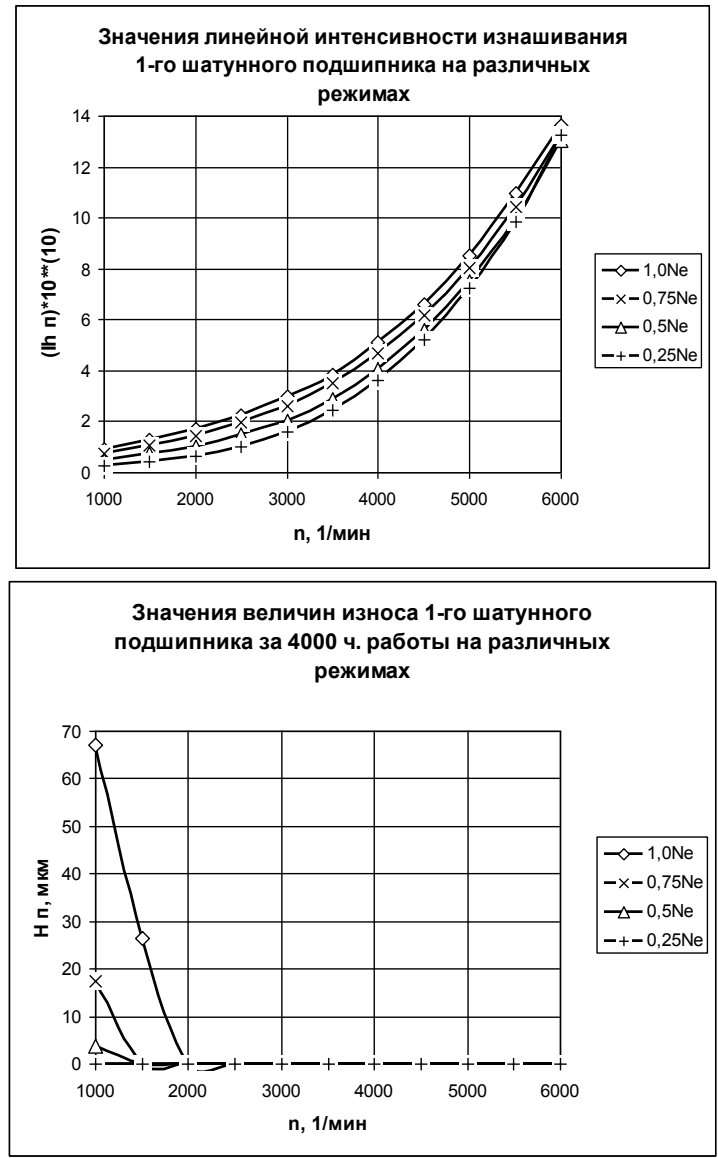

Рис. 2. Результаты оценочных расчетов на износ шатунного подшипника ВАЗ-2112

Исходные данные для расчета были приняты следующие. Время работы двигателя $\tau_{д}=4000$ часов (соответствует ресурсу работы этого ДВС до первой переборки); расчет производился для числа оборотов от 1000 мин- $^{1}$ до 6000 мин $^{-1}$ с шагом 500 мин- $^{1}$ и нагру- зочных режимов 25, 50, 75 и 100\% номинальной нагрузки. В качестве примера приведем расчет одной из искомых точек (для частоты вращения коленчатого вала $\mathrm{n}_{д}=5500$ мин $^{-1}$ ). Режимные параметры: значение среднего давления, действующего на шатунную шейку на данном скоростном режиме, $\mathrm{P}_{\text {ср ш }}=19,71 \cdot 10^{5}$ Па. Геометрические параметры: $\mathrm{d}_{\mathrm{B} ш}=47,8$ мм (диаметр шатунной шейки); $1_{\Pi}=20$ мм (длина шатунного подшипника); $\mathrm{x}_{\Pi}=1,73$ мм (толщина подшипника); $\mathrm{e}_{\mathrm{p}}=25$ мкм (радиальный установочный зазор). Параметры материалов поверхностей трения: $\mathrm{E}_{\mathrm{M} \Pi}=60800 \mathrm{MПа}, \quad \mathrm{E}_{\mathrm{T}}=108000 \mathrm{MПа} ; \quad \mu_{\mathrm{M}}=0,32$, $\mu_{\text {т в }}=0,22 ; k_{\text {п }}^{\prime}=3$ (эластичный материал), $\mathrm{k}_{\mathrm{B}}^{\prime}=4$ (хрупкий материал); $\Delta_{\Pi}=8,6 \cdot 10^{-3}, \Delta_{B}=3,1 \cdot 10^{-3}$ (приработанные поверхности); $\quad \tau_{0 \Pi}=0,5 \mathrm{MПа}, \quad \beta_{\Pi}=0,03$, $\tau_{0 \mathrm{~B}}=0,5 \mathrm{M} а, \beta_{\mathrm{B}}=0,03 ; \sigma_{\mathrm{B}}=430 \mathrm{MПа}, \sigma_{\mathrm{B}}=900 \mathrm{MПа}$; $\mathrm{t}_{\Pi}=6,9, \mathrm{t}_{\mathrm{B}}=9$.Расчетное контурное давление при этих данных $\quad \mathrm{P}_{\mathrm{C} \text { ш }}=49,88 \mathrm{MПа}, \quad$ угол контакта $\varphi_{0 \text { ш }}=0,228$ рад $=13,048^{\circ}$; внутренний диаметр подшипника $\mathrm{d}_{\text {п ш }}=47,85$ мм. Линейная интенсивность изнашивания подшипника при этих условиях:

$$
\begin{aligned}
& I_{h n}=\left[\frac{034, k_{n}^{\prime t_{n}} \cdot\left(-\mu_{M n}^{2}\right)^{2} \cdot P_{C u}}{\sigma_{B n}^{t_{n}} \cdot E_{M n}}\right] . \\
& \cdot\left[\tau_{0 n}+0,5 \cdot \beta_{n} \frac{P_{C u}^{\frac{1}{5}} \cdot E_{\mathcal{M} n}^{\frac{4}{5}} \cdot \Delta_{b}^{\frac{2}{5}}}{\left(-\mu_{M n}^{2} \stackrel{4}{\frac{4}{5}}\right.}\right]^{t_{n}}= \\
& =\left[\frac{0,34 \cdot 3^{6,9} \cdot\left(-0,32^{2}\right) \cdot 47,77 \cdot 10^{6}}{\left(30 \cdot 10^{6}\right)^{2,9} \cdot 60800 \cdot 10^{6}}\right] \text {. }
\end{aligned}
$$

$, 5 \cdot 10^{6}+0,5 \cdot 0,03$

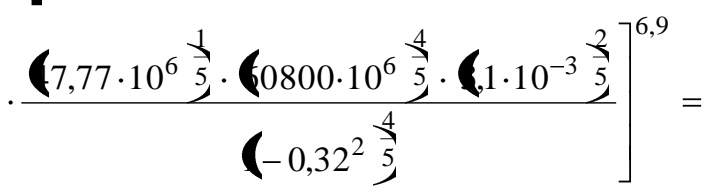
$=1,095 \cdot 10^{-9}$.

Интенсивность износа равна $\mathrm{I}_{\mathrm{h}}=4,069 \cdot 10^{-12}$. Эти значения соответствуют экспериментальным данным по рассматриваемому классу автомобильных двигателей [7]. На данном режиме работы ДВС подшипниковый узел работает в условиях гидродинамической смазки. Зон полусухого трения нет, изнашивания не происходит, несмотря на большее значение интенсивности изнашивания, чем при более низких частотах вращения (см. рис. 2). При частотах вращения до 2000 мин $^{-1}$ подшипниковый узел работает частично в условиях граничного трения, что иллюстрирует второй график (рис. 2). Величина износа подшипника оценивалась по следующей формуле:

$$
\Delta H_{n}=I_{h n} \cdot n_{\partial} \cdot \tau_{\partial} \cdot 60 \cdot \varphi_{0 u} \cdot d_{n u} \cdot \xi_{u},
$$


где $\xi_{ш}$ - доля полусухого трения (при задаваемой минимально допустимой толщине масляного слоя, например, для данного расчета $\mathrm{h}_{\mathrm{m} \text { min }}=2$ мкм). Следует отметить, что приведенный расчет носит оценочный характер, поскольку, как отмечалось выше, не учитывает долей времени работы ДВС на эксплуатационных режимах и неустановившихся режимах работы. Тем не менее, метод позволяет проследить влияние геометрических, режимных и части эксплуатационных параметров (вязкости, теплоемкости и температуры масла, давления и температуры окружающей среды и ряда других) на изнашивание. Дело в том, что расчет на изнашивание подшипников скольжения невозможен без проведения следующих предварительных расчетов: масляной пленки на режиме работы (поиск $\mathrm{h}_{\mathrm{M} \min }$ ), динамики кривошипно-шатунного механизма (КШМ) (поиск $\mathrm{P}_{\mathrm{cp}}$ ). В свою очередь, перечисленные расчеты требуют данных расчетов рабочего процесса. Предлагаемая методика предусматривает комплекс перечисленных расчетов. Расчет величин изнашивания кольцевых уплотнений вместо расчета динамики КШМ предусматривает гидродинамический расчет поршневых колец, расчет температурных деформаций поршня и температуры в зоне колец.

Можно сделать вывод о том, что расчеты изнашивания на установившихся режимах работы подшипниковых узлов и кольцевых уплотнений ДВС дают достоверные результаты. Для уточнения расчетов величин износа необходимо дополнить данную методику статистикой времени работы двигателя на наиболее вероятных режимах эксплуатации, включая режимы холодного пуска и переходные. В результате такой комплексный расчетно-экспериметальный метод позволит прогнозировать с определенной долей вероятности ресурс ДВС по износу, как на этапе проектирования, так и при различных (изменяющихся) условиях эксплуатации.

\section{СПИСОК ЛИТЕРАТУРЫ}

1. Антропов Б. С., Цепенда М. В. Об использовании ресурса автомобильных дизельных двигателей // Двигателестроение. 1999. №4. С. 40-41.

2. Козырев С. П., Лельчук Л. М., Марон М. Е. и др. Методика оценки ресурса деталей машин по статистическим данным об их изнашивании в условиях эксплуатации // Теория и практика расчетов деталей машин на износ. М.: Наука, 1983. C. $135-141$.

3. Григорьев А. Н., Черепанов Д. А., Шабанов А. Ю. Анализ применимости различных моделей износа к условиям работы трибологических сопряжений ДВС // Материалы межвузовской научной конференции «XXVIII Неделя науки СПбГТУ». СПб, 1999.

4. Григорьев А. Н., Черепанов Д. А., Шабанов А. Ю. Расчетные методы и проблемы прогнозирования износа трибологических сопряжений ДВС // Материалы межвузовской научной конференции «XXX Неделя науки СПбГТУ». СПб, 2001.

5. Григорьев А. Н., Черепанов Д. А., Шабанов А. Ю. Проблемы определения длин путей трения в трибологических сопряжениях ДВС // Материалы межвузовской научной конференции «XXX Неделя науки СПбГТУ». СПб, 2001.

6. Крагельский И. В., Михин Н. М. Узлы трения машин: Справочник. М.: Машиностроение, 1984.

7. Крагельский И. В., Добычин М. Н., Комбалов В. С. Основы расчетов на трение и износ. М.: Машиностроение, 1977. 